\title{
O contexto cultural de Galileu e os agentes imersos na legitimação de sua profissão como filósofo-matemático
}

\section{Galileos cultural context and the agents involved in the legitimization of his professional role as a philosopher-mathematician}

\author{
MAGALI BRAVO VILLAMIL \\ Universidade Federal do ABC | UFABC \\ MÁRCIA HELENA ALVIM \\ Universidade Federal do ABC | UFABC
}

\begin{abstract}
RESUMO Os estudos de Galileu são reconhecidos por diversos historiadores, especialmente devido sua proposta de geometrização do comportamento dos corpos físicos em sistemas mecânicos. Porém, consideramos que esse processo não se restringiu às discussões exclusivas ao âmbito da Filosofia Natural, mas também quanto à validação da relação desta com a geometria, sofrendo a influência de agentes e dinâmicas sociais, dentre as quais encontramos um Galileu político, intervindo em espaços como as Cortes Italianas e o Collegio Romano. Assim, este artigo tem como objetivo analisar os vínculos estabelecidos por Galileu com esses agentes sociais que intervieram e promulgaram a legitimação das matemáticas nos estudos da Filosofia Natural.
\end{abstract}

Palavras-chave Galileu Galilei - corte italiana - Clavius - filosofia natural - geometria.

\begin{abstract}
Galileo's studies have been recognized for many historians for his geometrization of the behavior of physical bodies in mechanical systems. However, we believe this process was not restricted to exclusive discussions of Natural philosophy scope about the validity of its relation with the geometry, but, had the influence of agents and social dynamics, here we find a political Galileo that intervened in social places like the Italian Real Court and the Collegio Romano. So, this article aims to analyze the relations established by Galileo with these social agents that intervened and enacted the legitimacy of mathematics in the natural philosophy studies.
\end{abstract}

Keywords Galileo Galilei - Italian court - Clavius - natural philosophy-geometry.

\section{Introdução}

A revolução científica tem sido um período de diversos estudos no campo da história das ciências, apesar do nosso objetivo não se propor a realizar uma discussão sob esse tema, algumas das visões desta nos ajudam a entender a importância do trabalho intelectual e social de Galileu. Assim, para estudiosos como Cohen ${ }^{1}$ falar sobre a revolução 
científica, leva a propor perguntas como: Seria adequado atribuir o termo de revolução à transformação científica? Quando e onde teve inicio esse período? Continuando com Cohen, alguns estudiosos têm situado a origem deste período em 1543, ano no qual se publicou a obra de Vesálio sobre o corpo humano; outros se referem a Copérnico e seu tratado sobre as revoluções das esferas celestes, outros ainda, acreditam que os estudos de Galileu e Kepler sobre astronomia são um bom ponto de partida.

0 que se quer ressaltar a partir disto é que Galileu tem sido vinculado por alguns historiadores a tal período, e um dos juízos atribuídos ao porque desta vinculação, são seus estudos sobre astronomia retomando aspectos da perspectiva de Copérnico. Drake² vincula Galileu a esse período, porém, distingue-0, não pelos avanços teóricos nas ciências astronômicas, mas sim pelo aumento da utilidade que este concedeu à ciência. Embora essa perspectiva seja relevante, entendermos que nesse contexto as técnicas e desenvolvimentos mecânicos tiveram diversos significados, ou seja, o significado do conhecimento científico não se generalizou em todos os ambientes culturais de tal época a ser sinônimo de progressos mecânicos e técnicos, em outras palavras, o significado dos conhecimentos, em particular os mecânicos, é relativo dependendo da dimensão cultural em questão.

Com esse panorama, é possível estabelecer uma série de questionamentos que dirigem a intencionalidade deste artigo: Como se constitui o compromisso intelectual de Galileu como a proposta teórica de Copérnico? Quais foram os fatores que impulsaram Galileu a estudar os astros? Qual foi a magnitude dos alcances astronômicos de Galileu para destacá-lo historicamente? Quais fatores influenciaram a legitimação de suas observações? Acreditamos que estas questões evidenciarão a relação entre os saberes físico - matemáticos, promovendo uma reflexão que vai além do recorte totalmente intelectual e filosófico, favorecendo discussões sobre diferentes ambientes da sociedade renascentista.

\section{Ambientes e agentes políticos imersos nas discussões sobre a legitimação das matemáticas nos séculos XV-XVII: o Collegio Romano e as cortes florentinas}

A física e a matemática são dois saberes que na atualidade possuem um vínculo de coexistência, porém, as diferentes perspectivas de filósofos dos séculos XV ao XVII e algumas dinâmicas anteriores, nos mostram que essa relação nem sempre existiu, mas, vivenciou um processo complexo de consolidação política e intelectual. Portanto, o objetivo desta reflexão é analisar diferentes acontecimentos sociais contemporâneos a Galileu, os quais esboçam suas dimensões política e social influentes em seu desenvolvimento como intelectual e intervieram na legitimação da relação Filosofia Natural - Geometria no seu contexto.

Desde meados do século XIII, é possível identificarmos algumas limitações e problemáticas sobre a relação destas duas ciências, as quais esboçam algumas características da perspectiva das matemáticas durante parte do período medieval e, por sua vez, justificam as dificuldades que teve para sua divulgação em espaços acadêmicos universitários daquele período. Segundo Grant ${ }^{3}$, por exemplo, na universidade de Paris do século XIII, as matemáticas faziam parte das disciplinas que ocasionalmente tinham uma atenção regular ou continuada, diferente da filosofia de tradição Aristotélica.

Embora existissem na Idade Média numerosas obras de aritmética, geometria, astronomia e música, muitas traduzidas do árabe ou do grego, só um número limitado fazia parte dos textos obrigatórios nos cursos universitário.$^{4}$

Continuando com Grant, as disciplinas que estruturavam as universidades medievais ofereciam aos futuros mestres ou estudiosos, títulos dentro dos quais excluía-se a matemática. Portanto, títulos de Mestres em Teologia, Medicina e Direito eram aos quais se acessava despois de obter o título em artes. Ainda considerando que as mate- 
máticas tinham um lugar dentro das disciplinas do Quadrivium, pode-se destacar que essa separação conhecida como o Trívium e o Quadrivium, ressaltava o distanciamento e a demarcação entre os saberes concernentes à natureza e aqueles denominados como técnicos ou matemáticos, e esta demarcação do século XIII parece consolidar-se ainda mais devido as modificações nas disciplinas do currículo de artes, consequência da tradução e introdução de diversas obras Aristotélicas. Embora que de forma similar algumas das disciplinas contidas no Quadrivium, como a aritmética, a geometria e a astronomia, foram enriquecidas por esse movimento, as disciplinas do Trivium, consolidaram-se mais significativamente, adotando as diversas obras Aristotélicas nas distintas áreas, posicionando-se como saberes relevantes até por volta dos séculos XV e XVI.

0 interesse em enunciar essas características de três séculos anteriores a Galileu consiste em evidenciar que a relação atual entre essas duas ciências foi fruto de um longo processo que vivenciou múltiplas transformações em diferentes espaços da sociedade. Além disso, as mudanças que se iniciaram desde meados do século XV, não sucederam simultaneamente na Europa, ou seja, o papel e o significado dos saberes que abarcam as matemáticas, tanto para a academia como para a comunidade, envolveram diversas instituições e diferentes dinâmicas de reconhecimento.

Em Oxford, as ciências exactas tornaram-se parte integrante do currículo a partir do século XIII, mas foi-lhes conferida muito menos importância em Paris e noutros locais. Em Paris, a matemática e as outras ciências do quadrívio raramente faziam parte do que era proposto no curso regular. A matemática, por exemplo, não era habitualmente ensinada em Paris no século XII e só o foi, embora de forma esporádica no século XIV. ${ }^{5}$

Porém, esses fatos não são sinônimos de homogeneidade de pensamento. No século XII encontramos diversos filósofos como Jordano de Nemore e seu estudo sobre a estática, no qual a geometria o influenciou de forma notória, Roger Bacon, quem ressaltou a geometria em seu uso para a compreensão da natureza e Robert Grosseteste quem, em sua compreensão sobre o universo, assumiu uma interpretação geométrica, como válida e necessária. Visões importantes de ressaltar já que no século XVI foram retomadas por filósofos e matemáticos como Copérnico que evoca e destaca o uso da geometria na organização geométrica do universo, proposta por Ptolomeu.

Como quase todos os seus predecessores, Ptolomeu adota um sistema geocêntrico - ou, mais exatamente, geostático, pois a Terra, embora imóvel não seja o centro de todos os movimentos dos orbes. Ptolomeu diferenciou-se de seus predecessores, no entanto, em dois importantes aspectos: (a) o uso totalmente livre de todos os tipos de recursos matemáticos (excêntricos, epiciclos, equantes etc) sem qualquer limitação de princípio em relação à simplicidade dos movimentos básicos. ${ }^{6}$

Arquimedes foi outro filósofo retomado no século XVI, por Galileu com seus estudos sobre a alavanca, fluídos e mecânica geral, onde geometriza tanto os corpos como as distribuições destes em determinados sistemas, baseado na geometria euclidiana. Essas tradições de Arquimedes, Ptolomeu e outros intelectuais, segundo Wallace, ${ }^{7}$ são relevantes nas discussões sobre a legitimação das matemáticas do século XVI. No desenvolvimento de novas leituras e traduções dessas tradições nos séculos XVI-XVII, Wallace ${ }^{8}$ e Dear ${ }^{9}$, destacam a participação da comunidade Jesuíta, a qual atuou significativamente no processo de legitimação das matemáticas, assim, como na vida intelectual de Galileu. Por isto, neste estudo, reconhecemos que os jesuítas do Collegio Romano foram partícipes deste processo, como na produção de material intelectual, influenciando o panorama sobre as discussões em torno dos matemáticos.

Clavius, professor de matemáticas do Collegio Romano durante o período de 1565 até 1612, foi um dos matemáticos jesuítas mais reconhecidos pelos historiadores das ciências não só por seus estudos em matemáticas, mas, também por sua particular visão sobre esta e as repercussões de sua proposta após sua morte. Quanto ao primeiro aspecto evidenciado em suas distintas intervenções intelectuais e sociais, em 1589, segundo Wallace, ${ }^{10}$ Clavius publica uma edição sobre os Elementos de Euclides, na qual tenta conectar as abordagens geométricas realizadas por Arquimedes, em estática e fluídos, e as de Ptolomeu em astronomia, com os teoremas propostos por Euclides o qual teria influência nos estudos de matemáticos posteriores. Assim, para Wallace, ${ }^{11}$ Blancanus é um exemplo da influência 
de Clavius ao publicar uma obra apresentando procedimentos e passagens dos trabalhos de Aristóteles que admitiam 0 uso das matemáticas.

Entendendo que para reconhecer esse processo de Clavius em relação à valorização das matemáticas desde suas obras seria necessário 0 acesso as fontes originais, interessa-nos neste momento destacar como essas ações põe em evidência seu interesse em abordar uma das causas centrais do baixo status das matemáticas, a qual se centrava em sua articulação com outras disciplinas, ou seja, seu objetivo de desestabilizar as limitações estabelecidas pelas universidades medievais, fato que colaboraria para a promoção da imagem dessa disciplina. Assim, o êxito de suas ações, bem como sua influência social, evidencia-se em dois aspectos: as posteriores transformações que se deram nos espaços acadêmicos do Collegio Romano e o surgimento e influência na formação de outros matemáticos.

Referente às transformações nos espaços académicos, segundo Dear ${ }^{12}$ Clavius foi um dos mais importantes matemáticos jesuítas promotores da inserção das matemáticas nos currículos académicos (como fundamentais para a compreensão de outras disciplinas), no que se refere aos colégios romanos, caracterizados por serem prestigiosas instituições educacionais da Europa Moderna. Por razões como essas, os matemáticos jesuítas são considerados por Feldhay ${ }^{13}$ como os primeiros a realizarem o esforço de institucionalização das disciplinas matemáticas nesse contexto cultural. Assim, promover um lugar significativo às matemáticas nos espaços educacionais jesuítas, segundo Dear, ${ }^{14}$ foi um avanço exitoso que se diferencia dos formatos medievais, criando a possibilidade e a necessidade de um aumento na formação de professores em matemáticas, sendo Galileu um reflexo da formação de matemáticos influenciados pelos interesses jesuítas.

The debate over the status of mathematics in the sixteenth century signaled the beginning of a structural shift on the medieval map of knowledge toward a different understanding of the place of mathematics. The change was initiated by a variety of separate developments such as the activities of mathematical practitioners in Italian courts, the renaissance of Greek mathematical texts, the spread of Archimedean discourse, the emergence of Copernican astronomy, and the rise of the new algebra. ${ }^{15}$

Desta forma, Feldhay aponta que este debate sobre as matemáticas e sua relação com a Filosofia Natural, expandiu-se na Itália em meados do século XVI, através do debate que se centrou na discussão sobre a validez dos critérios das práticas dos matemáticos no estudo da Filosofia Natural. Inserimos Galileu neste debate não somente pela repercussão intelectual de suas obras sobre astronomia, mecânica e outras, como também, por seus procedimentos para desenvolvê-los e legitimá-los. Neste sentido, se tornam relevantes seus vínculos com estudiosos e governantes particulares.

Wallace ${ }^{16}$ e Biagioli17 indicam os espaços como as Côrtes Florentinas e as instituições jesuítas, onde Galileu e outros matemáticos intervieram e interagiram com outros intelectuais, como Ostilio Ricci, um especialista em matemática aplicada e engenharia militar, pertencente à Corte do grão-duque Francesco de Florência, ditava aulas aos membros da Corte Florentina da Accademia do Disegno, academia de Belas Artes patrocinada pela Corte Florentina dos Médici. Nesse contexto Galileu conheceu Ricci quando este apresentava uma conferência sobre Euclides no espaço da Corte Florentina. Esse vínculo entre Galileu com Ricci e Clavius, dá luzes ao início de sua formação e, talvez, do porquê de suas investigações dialogarem com o caráter matemático encontrado em Euclides e Arquimedes. Essa formação lhe permitirá iniciar sua carreira como integrante da cultura sócio-profissional dos matemáticos.

Galileu passou por volta de quatro anos envolvido no estudo das matemáticas aplicadas, sob a tutoria de Ostilio Ricci. Neste processo, historiadores como Wallace ${ }^{18}$ e Biagioli ${ }^{19}$ encontram na vida acadêmica e social de Galileu uma influência notória de Ricci e Clavius. Isso, o sustentam através de vários aspectos: no contexto acadêmico, de acordo com Wallace ${ }^{20}$ para criticar uma filosofia há um requisito que é conhecê-la, e essa é a base da primeira etapa intelectual de Galileu, a respeito da Filosofia Natural, na qual Clavius interveio fornecendo-lhe parte da cultura intelectual pertencente ao Collegio Romano. Foi através dele que, possivelmente, Galileu adquiriu seu amplo domínio na filosofia de tradição Aristotélica, obtendo um conjunto de leituras de Filosofia Natural, conforme Wallace, ${ }^{21}$ "provavelmente através de esta avenida (Clavius) Galileu tem possessão de uma cópia de notas de leituras sobre lógica que têm sido 
completadas por outro filosofo jesuíta do Collegio Romano, Paolo Valla" Em 1589 Clavius envia-lhe notas de Valla sobre as obras Meteorologia e De generaitone, junto com comentários das leituras realizadas por Antonio Menu e Muzio de Angelis das obras, A física de Aristóteles e Sobre os céus. Isto nos indica que as intervenções e conhecimentos de Galileu tomam lugar dentro do contexto Aristotélico difundido no Collegio Romano ao redor de 1590.

Em 1589 a influência de Clavius se reflete em um plano menos acadêmico junto a amizade de Guidobaldo do Monte, obtendo um lugar como professor de matemáticas, astronomia e mecânica na universidade de Pisa e de Pádua em 1591. Apesar de Galileu não contar com um título outorgado por alguma instituição, seus estudos com Ricci foram suficientes para vincular-se como professor, isto mais uma vez reflete a importância da influência social de Guidobaldo e de Christopher Clavius, além do fato de que Galileu ministrou e desenvolveu estudos nessas disciplinas, evidenciam uma linha de pensamento similar à de Clavius, tentando promover a imagem das matemáticas através da ruptura dos limites entre matemáticas e outras disciplinas.

Todos esses intentos que se vinham realizando, desde a Idade Medieval, relacionando ciências como a estática e a astronomia com a geometria, e inserindo-as em livros de divulgação e em currículos acadêmicos do século XVI, permitem-nos ter um panorama onde se apresentam diversas possibilidades do como pôde dar-se essa relação entre geometria - filosofia. Ou como afirma Kuhn, ${ }^{22}$ essas diversas relações possibilitaram estabelecer diálogos entre suas linguagens e suas estruturas lógicas. Além desses diversos esforços, as contribuições provenientes de Clavius e Ricci, configuram ao Collegio Romano e as Côrtes, em especial as italianas, como dois espaços culturais fundamentais que intervieram no desenvolvimento da obra e status de Galileu, consolidando-o como agente partícipe do processo de legitimação das matemáticas.

Para os séculos XVI - XVII, segundo Biagioli, ${ }^{23}$ os estudos dos matemáticos, ainda estavam sujeitos às limitações e inconformidades definidas pelos filósofos de tradição aristotélica, de maneira que os matemáticos continuavam atuando em um campo delimitado de intervenção intelectual em comparação com a intervenção de diferentes filósofos em espaços sociais e acadêmicos, pelo qual, as reflexões que esses propiciaram a respeito do comportamento dos fenômenos físicos, continuavam apresentando dificuldades no momento de serem considerados para sua divulgação e ensino.

Copérnico, por exemplo, é um dos matemáticos reconhecidos deste período, em especial, por sua organização astronômica, a qual alguns historiadores ressaltam que não foi divulgada ou aceita por sua discrepância com as afirmações teológicas, porém, concordamos com Biagioli, ${ }^{24}$ ao pensar que essas distinções e limites entre filósofos e matemáticos mantêm, além dos interesses intelectuais, interesses políticos específicos, que podem ser considerados como fatores causantes de sua proibição, já que aceitá-la implicava ratificar os critérios matemáticos como superiores aos filosóficos, e, portanto, dar-lhes, aos matemáticos, um posicionamento social similar ao dos filósofos. Disto que, no marco das discussões intelectuais, algumas instituições acadêmicas, deslegitimavam as afirmações dos matemáticos apresentando-as a seus estudantes como provenientes de uma disciplina inferior à filosofia, e Clavius, segundo Dear, ${ }^{25}$ consciente desta ação em 1580 dirige-se a debater com os professores que apresentam tais afirmações difamatórias, como a afirmação de que as ciências matemáticas não são ciências, ou que não têm demonstrações. Sob essas problemáticas, estabeleceu-se como requisito para ser professor de matemáticas do Collegio Romano, aceitar que as matemáticas são parte integral da filosofia e que não são simples conjuntos de técnicas de cálculo.

Isto reflete que nas dinâmicas deste período, o poder não só se reduz a uma forma material ou como afirma Biagioli, ${ }^{26}$ o poder não é uma "coisa" externa ao processo de criação do conhecimento, senão, que se encontra imerso tanto nas práticas ou discursos que os diversos atores culturais constroem, como nos alcances ou repercussões que esses manifestem nos múltiplos ambientes de uma sociedade.

[...] el poder se encuentra muy arraigado en los modales, la disciplina y la cortesía del discurso. Así mismo, saben que a pesar de su apariencia delicada, éste es un factor muy eficaz para la formación de las ideas, la conducta y la identidad individual. A su vez, el poder no existe por fuera de esas prácticas, como una especie de causa independiente, sino que se constituye en ellas ${ }^{27}$ 
Aceitar o sistema de Copérnico pode ter sido sinônimo de considerar as afirmações provenientes dos matemáticos, elevando-as ao mesmo nível de importância daquelas propostas pelos filósofos, implicaria modificações nos sistemas acadêmicos estabelecendo espaços para a formação em geometria, pois, segundo Kuhn ${ }^{28}$ para Copérnico "As matemáticas se escrevem para matemáticos". E, por estar imersas em sua organização sobre o universo, a formação em matemáticas seria quase que obrigatória para os filósofos, pois essa daria conta da ordem e mudança dos corpos celestes, ou seja, a geometria explicaria a dinâmica do universo.

Com essas hierarquias profissionais e limitações, percebe-se outros aspectos históricos, evidenciando que a matemática nem sempre foram considerada como um saber de alto status intelectual que deve ser estudado nas instituições formadoras. Além disso, sua relação com a física nem sempre existiu, senão, que surgiu de um processo intelectual e social.

\section{O espaço da corte dos Médici e a dimensão política-intelectual de Galileu}

Nesta parte pretende-se reconstruir a identidade política de Galileu ou, em outras palavras, reconhecê-lo como um homem com identidade social que atuou e se envolveu com as dinâmicas sociocultural de sua época, que de diversas formas dirigiram, condicionaram e influenciaram sua ação como filósofo natural. Este argumento apresenta-se como parte importante deste estudo, pois não se pretende analisar de forma exclusiva Galileu como um filósofo distante de sua identidade sociocultural.

Segundo Burke ${ }^{29}$ devido as limitações e dificuldades dos matemáticos provenientes dos centros acadêmicos para serem valorizados profissionalmente, como para contemplar seus saberes de forma tal que pudessem intervir na descrição dos fenômenos físicos e serem divulgados, a universidade manteve a intervenção de professores e estudantes que teriam vínculos diretos com agentes do clero e, estes vínculos, foram respaldo importante que justificava a superioridade e credibilidade dos filósofos. Igualmente, segundo Brzozowski ${ }^{30}$ esse privilegio refletia-se nas cátedras, quase de forma exclusiva para a difusão da filosofia Aristotélica. De forma que, a universidade foi um espaço de choques de benefícios, direitos e limitações, com pouco acordo com os interesses dos matemáticos.

Embora, os benefícios ou privilégios, os quais contavam os filósofos, em parte provinham dessa instituição, Biagioli ${ }^{31}$ evidencia que existiam outras organizações políticas locais as quais foram influentes em seus respectivos reinos, com os governadores seculares que também tiveram um rol importante em relação à concessão de benefícios a seus integrantes, similares aos oferecidos pelo clero aos filósofos. Oferecendo-Ihes um contexto cultural, político e econômico, diferente ao religioso, o que possivelmente brindou uma série de possibilidades e condições para que os matemáticos desenvolvessem seus estudos em um "ambiente de maior liberdade".

Em 1605, de acordo com Biagioli, ${ }^{32}$ Galileu é recomendado pelo médico cortesão da família dos Médici, Mercuriale. Apesar de Galileu já ter contato com essa família quando conheceu Ricci, Mercuriale intercedeu não para obter um posto universitário como Ricci o fez, mas, sim, para iniciar relações diretas com essa Corte, sendo professor pessoal de matemáticas do jovem Cosme, filho da Duquesa Cristina de Lorena. Embora esse cargo fosse temporal permitiu-lhe realizar uma série de ações, como a dedicação ao manual sobre o compasso militar, fortalecendo sua relação com o jovem Cosme e com sua genitora, a Duquesa Cristina. Isto reflete a importância do papel dos vínculos que Galileu consolidou ao longo de sua carreira, permitindo-Ihe ser o professor particular do filho do Duque, homenagear à família Médici, portanto, conhecer e agir nas dinâmicas internas da Corte, construindo sua imagem dentro da mesma.

Ser membro de uma das instituições sociais mais reconhecidas na Europa poderia servir como caminho para continuar com o objetivo de Clavius, ou seja, promover uma disciplina que era questionável pelos filósofos, e isso fazia parte do caminho escolhido por Galileu, ao migrar da universidade à Corte Florentina. Esse trânsito permitiu-lhe dialogar com outros agentes culturais, o que levou a assumir limitações distintas àquelas mencionadas pelos filósofos universitários, pois, nesses espaços os príncipes ou nobres eram os que propunham perguntas ou polêmicas de problemas de 
diferentes fenômenos, dando-lhe, ao matemático cortesão, a responsabilidade de solucioná-las. Aliás, a importância que os matemáticos assumiram nessas polêmicas, segundo Dear, ${ }^{33}$ foi uma intervenção significante para Clavius que permitiria a promoção de uma imagem apropriada das matemáticas.

Por lo tanto, la corte es un ámbito social en el que los matemáticos pueden adquirir una mejor posición social y una mayor credibilidad, con lo cual contrarrestan la brecha disciplinaria que los divide de los filósofos. A su vez, esa elevación del estatus social y disciplinario contribuiría con la legitimación de la nueva cosmovisión propuesta por ellos. ${ }^{34}$

Essa mudança de ambiente proporcionou diferenças no significado dos saberes dos matemáticos, exemplo disso, são os matemáticos Cardano e Tartaglia que por volta de 1540 a 1550, apresentaram a solução da equação de terceiro e quarto graus. Mesmo assim, segundo Biagioli, ${ }^{35}$ isso não parecia melhorar o status social dos matemáticos, não porque esse estudo carecesse de importância ou significado para o grupo dos matemáticos, senão, porque esse significado divergia daquele realizado no campo da Corte, pois não dialogava com problemas sociais ou outros mais próximos a seus interesses. E isto se torna evidente quando se geram avanços técnicos específicos em artilharia, que repercutiram nas disputas políticas do século XVI, nas quais Tartaglia também interveio, sendo um dos matemáticos que participou no campo da balística, segundo Delumeau, ${ }^{36}$ a inclinação na qual deve estar o canhão para que esse tenha seu máximo alcance teria que ser de $45^{\circ}$ graus na horizontal. Essa segunda intervenção de Tartaglia, envolveu dinâmicas de carácter social e teve evidentes repercussões no reconhecimento dos saberes dos matemáticos.

Acreditamos que além desse reconhecimento, essa intervenção dos saberes matemáticos no contexto social dos séculos XV a XVII é um fato que apresenta esse conhecimento não sendo organizações que surgem, se consolidam e se concretizam de forma exclusiva na mente do matemático, senão que intervêm e provêm de uma realidade acessível. Assim, enquanto na universidade as matemáticas são vistas como conhecimentos inferiores, na Corte, são significativas e necessárias para os interesses militares ou para as necessidades topográficas de distribuição de água, entre outros.

A dedicação de descobertas a serviço dos nobres e o particular significado destes saberes para os matemáticos, foram dinâmicas acolhidas por diversas Côrtes de diferentes reinos. Porém, Galileu manifestou uma disposição maior para com a Corte dos Médici, neste sentido, questionamos: Por que o interesse específico de Galileu em se envolver com a Corte dos Médici em Florença e não outra? Responder essa pergunta nos leva a destacar diversas características próprias dos Médici, uma das famílias poderosas de Florença que se vinha constituindo desde o século XV, e que para 0 século XVII, não só foi reconhecida por seus bens materiais, criação de academias, bibliotecas e outras, mas, também por suas amplas redes de contatos e influência em diferentes partes da Europa.

De acordo com um documento de 1458, época de apogeu do banco durante o governo de Cosme, o Velho, os Médicis eram accionistas maioritários em onze sociedades diferentes: em Florença, uma manufactura de seda e duas manufacturas têxteis, igualmente em Florença, a filial de Veneza, a de Bruges, a de Londres, a de Genebra [...] a filial de Roma. ${ }^{37}$

A influência e imagem dos Médici fazia da Corte um lugar apropriado para os matemáticos, pois, além dos aspectos já ressaltados, existiam antecedentes de outros intelectuais, pintores, filósofos, matemáticos e médicos que tinham estado vinculados a esta, e que em conjunto com suas atitudes tinham dado lugar à construção de espaços como academias, que exaltavam não somente o nome do estudioso, mas também seu labor intelectual como o de seus colegas. Permite-se destacar Michelangelo como exemplo, que por seu talento como por seu vínculo com os Médici deu passo à legitimação das artes visuais.

La posición excepcional de ese artista constituye una herramienta que les permite presentar a toda la disciplina como poseedora de un estatus social elevado, algo de lo cual carecía hasta ese momento. De hecho la organización del funeral de Miguel Ángel en Florencia en el año 1564 está a cargo de la Accademia del Disegno, recién fundada como la primera academia oficial de bellas artes ${ }^{38}$ 


\title{
A respeito do funeral de Michelangelo e a intervenção dos Médici, Byington $^{39}$ afirma:
}

\begin{abstract}
A primeira realização da Academia é o imponente funeral de Michelangelo em julho de 1564, cerimônia que exigiu cinco meses de preparação. A solenidade homenageava o artista como a um soberano e se servia da biografia do "divino mestre" para celebrar em imagens a historia das artes sob o patrocínio da família Médici. ${ }^{40}$
\end{abstract}

Isso mostra que as intervenções intelectuais e sociais de Michelangelo, além de impulsionar a legitimação de seus saberes como o de seus colegas, evidencia uma relação onde há um acordo mútuo de legitimação de conhecimentos como de tradições, refletido em homenagens e atos particulares provenientes de cada parte, dinâmica próxima à dos matemáticos com a intervenção de Galileu.

\begin{abstract}
A descrição do majestoso funeral, no qual os artistas acadêmicos entravam perfilados atrás do lugar-tenente, segundo cerimonial solene, para ocupar lugares especiais na igreja superlotada, se empunha como uma ocasião sem precedentes. A imponente cerimônia, na igreja oficial da família Médici, celebrava Michelangelo feito um monarca. Ao honrar deste modo o artista morto, atribuía aos vivos novo status e nova distinção social. ${ }^{41}$
\end{abstract}

Michelangelo, por seu trabalho e status conferidos pela Corte dos Médici, foi um importante antecedente que, possivelmente, impulsionou Galileu a continuar com seus diversos esforços intelectuais e fortalecer seu vínculo com esta família. Todavia, isso permitiu reconhecer que no ambiente da Corte os saberes tornavam-se significativos a tal nível que recompensavam suas novidades constituindo lhes uma identidade sócio-profissional seja através da criação de academias, saldos consideráveis, ou presentes luxuosos, contrário aos benefícios que lhes brindava a academia.

De tudo isso, é evidente que os benefícios provenientes das relações entre filósofos com as Côrtes, contribuíram no processo de legitimação de sua profissão; assim, tem-se visto que fazer parte de um contexto cortesão expõe ao filósofo ou ao artista o cumprimento de funções divergentes daquelas estabelecidas pelos centros universitários, fornecendo a possibilidade do reconhecimento de seus saberes, por outro lado, temos visto que a relação com intelectuais reconhecidos como Ricci e Clavius permitiu a Galileu formar-se como matemático e filósofo natural, ascendendo à cultura intelectual do Collegio Romano, e conhecendo as discussões aristotélicas dadas ali.

Trabalhos artísticos como os de Michelangelo e outros desenvolvidos na Accademia do Disegno, consolidavam a imagem, a história e as tradições culturais da família dos Médici. A particularidade da homenagem feita por Galileu, ao dedicar os corpos girantes em torno de Júpiter, descritas no Mensageiro das Estrelas, diferencia-se das pinturas, esculturas, livros ou outro tipo de homenagem material e Galileu, consciente desta particularidade, distinguia-se dos demais matemáticos de forma singular através da legitimação da dinastia dos Médici.

Afirma Galileu:

E assim, passando para os céus, inscreveu naqueles conhecidos orbes eternos dos astros mais brilhantes os nomes daqueles que, por seus feitos ilustres e quase divinos, foram julgados dignos de disfrutar com as estrelas de uma vida eterna. Por isso a fama de Júpiter, Marte, Mercúrio, Hércules e outros heróis por cujos nomes as estrelas são designadas, não se apagará antes que o próprio resplendor das estrelas se extinga. ${ }^{42}$

Apesar do Mensageiro das Estrelas ser dedicado a Cosme ll e Júpiter tem correspondência com Cosme I, Galileu, insinua-Ihe a Cosme II que esse último tem-Ihe transferido suas virtudes e as de Júpiter através dos astros que descreve em sua obra, além disso, Galileu apresenta e harmoniza mais um argumento, através da coincidência do número de astros e o número de irmãos de Cosimo II. 
Según Galileo, lo observado no constituía un descubrimiento sino una confirmación del destino de los Medici, casi una prueba científica de lo que afirmaba el horóscopo dinástico. En la dedicatoria del Sidereus nuncius, Galileo comenta a Cosme II que no le parece casual que "los astros brillantes se ofrezcan al cielo" junto después de su coronación. Tampoco considera casual que dichos astros rodeen Júpiter (el planeta de Cosme) como si fueran sus retos, ... Además, se podría agregar que tampoco es casual la cantidad de los astros, que suman cuatro, al igual que Cosme II y sus hermanos. ${ }^{43}$

Esses conhecimentos em astronomia harmonizados com a perspectiva dos Médici tiveram valor significativo em uma dimensão simbólica e dinástica, uma legitimação ou reafirmação proveniente desde o divino e celeste do poder e autoridade da Corte dos Médici. Assim, conforme Biagioli, “El orden celestial legitima y naturaliza el orden terrestre... [em el caso de su relación con la família Médici], es la correspondencia especifica que se establece entre Júpiter (el mayor de los dioses) y Cosme I (el fundador del Gran ducado de Toscana)". ${ }^{44}$ Galileu consciente dessa correspondência exalta, em termos celestes, a Cosimo I como a sua descendência.

Eis, pois, quatro estrelas reservadas para o vosso nome ilustre, e não são elas da multidão das menos notáveis estrelas fixas, mas da ordem ilustre das estrelas vagueantes, que, com movimentos sem dúvida diferentes, fazem os seus percursos e orbitas com uma velocidade maravilhosa em torno da estrela de Júpiter, a mais nobre de todas elas, como sua autêntica descendência, enquanto todas juntas, em mútua harmonia, completam as suas revoluções cada doze anos em torno do centro do mundo, isto é, em torno do próprio Sol. ${ }^{45}$

Essa relação divina é enaltecida ao longo da obra através do uso de termos particulares como: "maravilhosa", "ordem ilustre", “a mais nobre", "autêntica", "harmonia", "heróis", "divinos", "brilhantes", "eternidade”, palavras que sublimam a majestade de suas observações e, ainda mais, do vínculo destas com a mitologia dos Médici.

[...] do mesmo modo que essas estrelas, como digna descendência de Júpiter, nunca se afastam do seu lado senão por pequena distância, assim, quem ignora que a clemência, a bondade de espirito, a gentileza das maneiras, o esplendor do sangue real, a majestade no agir e a amplidão da autoridade e mando sobre os outros, todas estas qualidades que acharam um domicílio e sede em Vossa Alteza, que, digo eu, ignora que tudo isto emana da benigna estrela de Júpiter. ${ }^{46}$

Conhecer a tradição mitológica da família Médici, foi um dos fatores que explicam porque Galileu insistiu em construir as relações necessárias para ser membro dessa e não de outra Corte, pois essa tradição permitiu-lhe vincular seus estudos de forma mais significativa, reafirmando, mais uma vez, tal vínculo, consciente da transcendência que 0 mesmo possuí para a Corte como para seus estudos.

En 1610 cuando el autor le dedica el hallazgo de los Astros mediceos a Cosme,...: el príncipe retribuye su obsequio con una medalla de oro y una cadena de valor relativamente bajo en comparación con los Astros, pero su verdadera recompensa es permitir que Galileo ingrese en una relación de mecenazgo privilegiada al nombrarlo matemático y filósofo principal de la corte. ${ }^{47}$

0 reconhecimento pelos alcances intelectuais de Galileu plasmados nessa obra não proveio somente da Corte dos Médici. Na primavera de 1611, segundo Wallace ${ }^{48}$, ocorreu uma solene convocação, celebrada no Collegio Romano, honrando a Galileu e suas descobertas, na qual estudantes e professores explicavam a importância de suas conclusões.

Galileu não se restringiu à dedicação dos astros, para a divulgação desses produziu diversos exemplares de sua obra como a construção de telescópios dando-os a diversos príncipes e cardeais europeus para que pudessem ver os astros Mediceos, por sua vez, para que outros estudiosos pertencentes a essas, os conhecessem. No entanto, Galileu ao divulgar desta maneira suas observações, não somente estava adquirindo a responsabilidade de defender seus argumentos intelectuais, como também, o nome dos Médici, pois, se no caso de que algum dos filósofos das 
outras Côrtes identificassem inconsistências em seus estudos, estaria em risco suas afirmações sobre 0 universo e seu instrumento, mas também a honra e a legitimidade da relação divino terrestre e a família Médici.

Por último, essa relação entre os Médici e Galileu, similar à estabelecida por Michelangelo, destaca uma legitimação mútua, a qual legitima tanto suas descobertas astronômicas, como estudos posteriores que envolveram à matemática e a filosofia, tanto quanto o trabalho de seus colegas matemáticos e beneficiários. Por parte da Corte, a adaptação dos astros ao discurso político ser-lhe-ia útil para legitimar sua imagem de poder e status.

[...] el desarrollo de la sociedad y la cultura cortesanas se cruza con el proceso de legitimación social de la ciencia. Mientras que los príncipes como Cosme tratan de fundar estados absolutos y necesitan representaciones que legitimen su poder, los matemáticos universitarios como Galileo se ven separados de los filósofos por una brecha social..., esta brecha deslegitima el uso de las ciencias matemáticas en tanto herramientas para el estudio de los fenómenos naturales en sus dimensiones físicas. Por lo tanto, del mismo modo que los artistas se habían transformado en académicos mediante la representación visual de la mitología del poder soberano, galileo se convertía en filósofo mediante la representación de los satélites de Júpiter como emblemas dinásticos. Aunque la corte no era una academia científica, si era una institución que podía ofrecer la legitimidad social necesaria para afirmar la credibilidad de los matemáticos devenidos en filósofos. ${ }^{49}$

Vale a pena esclarecer que nem todas as entidades da sociedade contemporânea a Galileu receberam com igual aprovação seus estudos, sendo criticado por alguns jesuítas por causa dessa obra, rejeitando suas observações e sendo essa uma causa do declínio de sua relação com estes. Wallace ${ }^{50}$ ressalta, por outro lado, que o alcance de outra perspectiva sobre os céus e seus corpos, fez evidente 0 apoio dos Aristotélicos progressistas como Clavius, sendo um dos seus primeiros defensores, ao construir um pequeno telescópio e tentando verificar os dados reportados por Galileu.

Esta visão sobre Galileu proposta por Biagioli, Wallace e outros, aqui discutidos, permitem refleti-lo como uma pessoa integral política e intelectualmente, com interesses pessoais e econômicos; que não foi um escravo da Corte, tampouco um manipulador de suas relações mercenárias, senão, um Galileu próprio de seu tempo, permeado e atuante em seu contexto, como o foi Kepler, Newton e outros. Assim, como afirma Biagioli51 seria útil desconstruir a ideia de que esses filósofos conseguiram o status que se atribui unicamente por seus estudos, e "substituí-la pela ideia de que esses títulos e seus mecenas os ajudaram também a obter credibilidade no plano de suas disciplinas".

\section{Considerações finais}

Neste estudo valorizamos uma visão sobre Galileu apresentando-o como uma pessoa integral, política e intelectualmente, com interesses pessoais e econômicos; não sendo um escravo da Corte, tampouco um manipulador de suas relações mercenárias, senão, um Galileu próprio de seu tempo, permeado e atuante em seu contexto. Acreditamos que a identificação dos aspectos históricos evidencia que a matemática nem sempre foi considerada como um saber de alto status intelectual que deveria ser estudado em instituições formadoras. Além disso, identificamos que sua relação com a física nem sempre existiu, senão, que surgiu de um processo intelectual e social. Outro ponto salientando neste estudo, refere-se a importância das relações entre filósofos, as Côrtes e reconhecidos intelectuais, que contribuíram no processo de legitimação de sua profissão. Assim, a partir da análise de Galileu acreditamos que pertencer a estes contextos forneceu a possibilidade do reconhecimento de seus saberes, e, além disso, das relações como aquelas estabelecidas com Clavius, Galileu adquiriu um compromisso em relação à legitimação do saber da Filosofia Natural e das matemáticas. Evidenciou-se, portanto, que a relação atual entre essas duas ciências vivenciou um longo processo, com múltiplas transformações em diferentes espaços da sociedade. Assim, o papel e o significado dos saberes que envolvem as matemáticas, tanto para a academia como para as Côrtes e a comunidade, envolveram diversos dinâmicas de reconhecimento intelectual, social e cultural. 


\section{Notas e referências bibliográficas}

Magali Bravo Villamil é licenciada em física pela universidade Pedagógica Nacional - Bogotá - Colombia. E mestra do programa de Pós- graduação Ensino, História e Filosofia das ciências e matemática. E-mail: msg19@hotmail.com.

Márcia Helena Alvim é historiadora, doutora em Ciências pela Unicamp e professora adjunta da Universidade Federal do ABC do programa de Pós-graduação Ensino, História e Filosofia das ciências e matemática. E-mail: marcia.alvim@ufabc.edu.br.

COHEN, B. La revolución newtoniana y la transformación de las ideas científicas. Madrid: Alianza, 1983.

2 DRAKE, S. Galileo. A very short introduction. Oxford: Oxford university press, 2001.

3 GRANT, E. et al. Os fundamentos da ciência moderna na idade média. Porto: Porto Editora, 2002.

$4 \quad$ Idem, p. 52.

$5 \quad$ Idem, p. 52.

6 COPÉRNICO, N. Commentarioulus- Pequeno comentário de Nicolau Copérnico sobre suas próprias hipóteses acerca dos movimentos celestes. Trad. Roberto de Andrade Martins. São Paulo: Editora Livraria da física, 2003. p. 64-65.

7 WALLACE, W. Galileo's Pisan studies in science and philosophy. In: MACHAMER, P. The Cambridge Companion to Galileo. Estados Unidos. Cambridge University, 1998. p. 27-52.

8 Idem.

9 DEAR, P. Jesuit mathematical scinece and the reconstitution of experiment in the early seventeenth century. Studies in history and philosophy sciences, v. 18, n. 2, 1987

10 WALLACE, W. Galileo and his sources: the heritage of the Collegio Romano in Galileo's science. Princeton: Princeton University Press, 1984.

11 Idem.

12 DEAR, P. Discipline \& Experience: the mathematical way in the scientific revolution. Chicago: University of Chicago Press, 1995.

13 FELDHAY, R. The use and abuse of mathematical entities: Galileo and the Jesuits revisited. In: MACHAMER, P. The Cambridge Companion to Galileo. Cambridge: Cambridge University Press, 1998. p. 80-145.

14 DEAR, P. Discipline \& Experience: the mathematical way in the scientific revolution. Chicago: University of Chicago Press, 1995.

15 FELDHAY, R. The use and abuse of mathematical entities: Galileo and the Jesuits revisited. In: MACHAMER, P. The Cambridge Companion to Galileo. Estados Unidos. Cambridge University, 1998. p. 89.

16 WALLACE, W. Galileo's Pisan studies in science and philosophy. In: MACHAMER, P. The Cambridge Companion to Galileo. Cambridge: Cambridge University Press, 1998. p. 27-52.

17 BIAGIOLI, M. Galileo cortesano: la práctica de la ciencia en la cultura del absolutismo, 1450-1600. Tradução por María Victoria Rodil. Buenos Aires: Editorial Katz, 2008.

18 WALLACE, W. Galileo and his sources: the heritage of the Collegio Romano in Galileo's science. Princeton: Princeton University Press. 1984.

19 BIAGIOLI, op. cit., 2008.

20 WALLACE, W. Galileo, the Jesuits, and the medieval Aristotle. Hampshire, Great Britain: Variorum; Brookfield, Vt.: Gower. 1991.

$21 \quad$ Idem, p. 354.

22 KUHN, Thomas, La tradición matemática y la tradición experimental en el desarrollo de la física. History of science. International Encyclopedia of the social sciences. New York, v. 14, p.74-83, 1968.

23 BIAGIOLI, op. cit., 2008.

24 Idem.

25 DEAR, op. cit., 1995.

26 BIAGIOLI, op. cit., 2008.

27 Idem, p. 14-15, prólogo.

28 KUHN, op. cit., 1968, p. 197.

29 BURKE, P. Uma História Social do Conhecimento: De Gutenberg a Diderot, Rio de Janeiro: Jorge Zahar editor, 2003.

30 BRZOZOWSKI, S. Tomás de Aquino e o conhecimento questao 84, artigos Ve VI da suma teológica. Santo André: Universidade Federal do ABC, 2013. 103 p. Tese (Mestrado)- Programa de Pós-Graduação em Ensino, História e Filosofia da Ciência da Matemática, Universidade Federal do ABC, Santo André, 2013.

31 BIAGIOLI, op. cit., 2008

32 Idem.

33 DEAR, op. cit., 1995.

34 BIAGIOLI, op. cit., 2008, p.19.

35 BIAGIOLI, M. Jesuit Science between texts and contexts. Studies in history and philosophy scinces, v. 25. N. 4, p. 637-646, 1994.

36 DELUMEAU, J. A civilização do Renascimento. Portugal: Ediçoes 70, 1984.

37 Idem, p. 211. 
38 BIAGIOLI, op. cit., 2008, p. 120.

39 BYINGTON, L. Giorgio Vasari e a edição das "Vidas": entre a Academia Florentina e a Academia do Desenho. Campina. São Paulo. 2011,321 p, Dissertaçao. Universidade Estadual de Campinas- Instituto de Filosofia e Ciências Humanas - Departamento de Historia. Campinas, 2011.

$40 \quad$ Idem, p. 172.

41 Idem, p. 176.

42 GALILEI, Galileu. Sidereus nuncius : o mensageiro das estrelas. Tradução por Leitão, Henrique. Lisboa, PRT: Fundação Calouste Gulbenkian, 2010, p.146.

43 BIAGIOLI, op. cit., 2008, p. 167.

44 Idem, p. 145.

45 GALILEI, op. cit., 2010, p.146.

$46 \quad$ Idem, p. 147.

47 BIAGIOLI, op. cit., 2008, p. 70.

48 WALLACE, op. cit., 1984.

49 BIAGIOLI, op. cit., 2008, p. 199.

50 WALLACE, op. cit., 1984.

51 BIAGIOLI, op. cit., 2008, p. 85.

[Recebido em Julho de 2015. Aprovado para publicação em Maio de 2016] 